when to screen women $<25$ years are needed. Such measures will help detect precancerous lesions and avert cervical cancer.

\section{P6.011 SURE START IN PUNE, INDIA: THE CONVERGENCE MODEL OF MATERNAL AND NEWBORN HEALTH AND HIV}

doi:10.1136/sextrans-2013-051184.1165

S Shankar Wunnava, L M Menezes. PATH, New Delhi, India

Background The Sure Start project is a seven year initiative implemented by PATH to improve maternal and newborn health and save lives in India. In Pune, Maharashtra, Sure Start focused on reducing maternal and newborn mortality rates and HIV among pregnant women, including the additional health care needs of HIV positive pregnant women. The objective was to raise awareness of HIV among pregnant women and motivate them to undergo HIV testing and to test the feasibility of convergence of HIV/AIDS and $\mathrm{MNH}$ for synergy in impact. Monitoring of Maternal and Newborn Status (MOMS) committees were involved for regular monitoring and follow-up in the community.

Methods A quasi-experimental study was conducted with preand post-intervention surveys, without a comparison group. Quantitative methods were used to capture changes associated with implementation of a Common Minimum Package and qualitative methods to assess model specific changes.

Results Percent of women who received three or more antenatal checkups increased from $83 \%$ to $97 \%$ from baseline to end-line, the percent of women initiating breastfeeding within one hour increased from $47 \%$ to $52 \%$ during the same period. Percent of women having institutional deliveries increased from $84 \%$ to $95 \%$. Percent of mothers who visited a health facility for a checkup during the postnatal period increased from $49 \%$ to $73 \%$. $92 \%$ of women had heard about HIV/AIDS, among these women 69\% knew about medication available to reduce the risk of transmission to a baby. Of $94 \%$ of those who knew about HIV/AIDS, $83 \%$ had undergone testing. Of the women advised to go for HIV testing $51 \%$ reported that flash cards used by Sure Start provided information about HIV.

Conclusion The model demonstrated the importance of MOMS committees in creating awareness and expanding knowledge. A convergence model helps in mainstreaming HIV positive women to avail of quality $\mathrm{MNH}$ care.

\section{P6.012 STI SCREENING AT HIV TREATMENT CENTRES FOR MEN WHO HAVE SEX WITH MEN CAN BE COST-EFFECTIVE}

doi:10.1136/sextrans-2013-051184.1166

${ }^{1,2}$ H J Vriend, ${ }^{1} A$ K Lugnér, ${ }^{1} M$ Xiridou, SSHIM (STI screening HIV-infected MSM) Working Group. 'National Institute for Public Health and the Environment (RIVM), Bilthoven, The Netherlands; '2Academic Medical Center (AMC), Amsterdam, The Netherlands

Background For HIV-infected men who have sex with men (MSM), implementation of routine STI screening into care at HIV treatment centres can substantially reduce STI incidence and possibly HIV incidence in the MSM population. Some countries already combine STI and HIV care, but its cost-effectiveness has not been explored. This study was designed to estimate the cost-effectiveness of providing routine anorectal chlamydia screening to MSM in care at HIV treatment centres in the Netherlands, where STI and HIV care are not currently combined.

Method Outcomes of a transmission model describing the sexual transmission of HIV and chlamydia in MSM over a 20 -year period were used as input for an economic model. Inclusion of multiple STIs were not allowed due to the complexity of the transmission model. The incremental cost-effectiveness ratio (ICER) was calculated for four scenarios: once- and twice-yearly routine chlamydia screening at HIV treatment centres among MSM who do/do not seek screening elsewhere.

Results Costs will be saved by routine chlamydia screening of MSM in care at HIV treatment centres if these patients seek little or no screening elsewhere. Opportunistic screening is considerably more expensive than routine screening offered within a scheduled visit. Adding once-yearly chlamydia screening for MSM in care at HIV treatment centres is cost-saving when $30 \%$ or fewer of those men seek once-yearly screening elsewhere. Twice-yearly routine screening at HIV treatment centres is cost-effective only when no opportunistic screening takes place.

Conclusion Adding annual chlamydia screening to the HIV consultation will be cost-saving as long as only a limited proportion of men are opportunistically screened. The ICER was most sensitive to the percentage of MSM that continue to be screened elsewhere.

\section{P6.013 RAPID HIV DIAGNOSTIC TESTING IN BRAZIL AND ITS CONTRIBUTION TOWARD REDUCING VERTICAL TRANSMISSION OF HIV AND SYPHILIS}

doi:10.1136/sextrans-2013-051184.1167

E Ayer, A Mello, A Bolzan, D Serafim, E Santos, L Pittaluga, S Vivaldini. Ministry of Health - Brasil, Brasilia, Brazil

Background In 2012, Brazil's Ministry of Health (MoH), via its Department of STDs, AIDS and Viral Hepatitis, increased the availability of rapid testing for HIV diagnosis and syphilis screening by means of a government programme called Rede Cegonha (the Stork Network), allowing for the strengthening of actions to promote, prevent, and assist STD/AIDS patients in the primary care network by servicing pregnant women during their prenatal visits, with the aim of reducing vertical transmission of HIV and syphilis.

Methods The $\mathrm{MoH}$ purchases and distributes rapid tests (RTs) produced domestically. The process was initiated by sensitising local managers to the need for implementing RTs in primary care units. Healthcare professionals were selected and trained to conduct RTs and to provide counselling. The RTs were delivered and introduced into the service routine in order to assist pregnant women and their sexual partners.

Results 27 states adhered to the programme, with 2,500 municipalities adopting the methodology and a total of 1,031 professionals being trained. In 2012, 3.7 million RTs for HIV and 1.1 million RTs for syphilis were distributed.

Conclusion The government's directive expedited the implementation process and the involvement of sanitary authorities. Rapid tests were found to be an agile and complementary tool in expanding access to diagnosis and speeding up the care needed to prevent and reduce vertical transmission of HIV and syphilis. This was an opportunity to update professionals and improve their approach, making it possible to provide integral care to pregnant women, their partners, and newborns.

\section{P6.014 KENYA'S PROGRESS TOWARDS ELIMINATION OF MOTHER- TO-CHILD TRANSMISSION (EMTCT) OF HIV}

doi:10.1136/sextrans-2013-051184.1168

'M A Mudany, ${ }^{2} \mathrm{M}$ Sirengo, 'L W Nganga, ${ }^{3} \mathrm{~A}$ Gichangi. ${ }^{1}$ Centers for Disease control and prevention, Nairobi, Kenya, ${ }^{2}$ National AIDS and STI Control Program (NASCOP), Nairobi, Kenya, ${ }^{3}$ Centers for Disease Control and prevention (CDC), Nairobi, Kenya

Background According to Kenya's Demographic Health Survey (KDHS) 2009, 6.2\% of 39 million residents are HIV-infected. Of 1.5 million annual pregnancies, 93,000 are HIV-infected. Without interventions, $35-40 \%$ of their infants would be infected. We describe Kenya's progress towards eMTCT. 